EGU2020-10185, updated on 19 Jun 2020

https://doi.org/10.5194/egusphere-egu2020-10185

EGU General Assembly 2020

(c) Author(s) 2020. This work is distributed under

the Creative Commons Attribution 4.0 License.

\title{
Contrasting seismogenic behaviors on the North Anatolian Fault in the Sea of Marmara
}

\author{
Pierre Henry ${ }^{1}$, Céline Grall ${ }^{2,6}$, M Sinan Özeren ${ }^{3}$, Volkan Özbey ${ }^{3}$, Gülsen Uçarkus ${ }^{4}$, Louis Géli ${ }^{5}$, \\ Valérie Ballu ${ }^{6}$, Ziyadin Çakir ${ }^{4}$, Semih Ergintav ${ }^{7}$, Dietrich Lange ${ }^{8}$, and Jean-Yves Royer ${ }^{9}$ \\ ${ }^{1}$ Aix Marseille Univ, CNRS, IRD, INRAE, Coll France, CEREGE, Aix-en-Provence, France (henry@cerege.fr) \\ ${ }^{2}$ Marine Geology and Geophysics, Lamont-Doherty Earth Observatory, Columbia University, New York, NY, USA \\ ${ }^{3}$ Istanbul Technical University, Eurasia Institute of Earth Sciences, Maslak, Istanbul, Turkey \\ ${ }^{4}$ Istanbul Technical University, Geological Engineering Dept., Maslak, Istanbul, Turkey \\ ${ }^{5}$ IFREMER, Centre de Brest, Géosciences Marines, Plouzané, France \\ ${ }^{6}$ La Rochelle Univ., CNRS, LIENSS, La Rochelle, France \\ ${ }^{7}$ Kandilli Observatory and Earthquake Research Institute, Department of Geodesy, Bogazici University, Istanbul, Turkey \\ ${ }^{8} \mathrm{Helmholtz}$ Centre for Ocean Research Kiel GEOMAR, Kiel, Germany \\ ${ }^{9}$ Laboratoire Géosciences Océan, Université de Brest and CNRS, Plouzané, France
}

Since the 1999 Izmit-Kocaeli earthquake, the Main Marmara Fault (MMF) of the North Anatolian Fault system in the Sea of Marmara has been considered at an imminent risk for a large earthquake. Land geodesy has difficulties characterizing the distribution of interseismic loading, and hence of slip deficit, on the offshore faults, and notably on the Istanbul-Silivri segment of the NAF. The need to clarify the status of offshore fault segments has motivated seafloor monitoring experiments and marine geophysical and sedimentological studies, notably in the framework of EMSO consortium and MARSITE and MAREGAMI projects. Results from cross-disciplinary projects have shown that aseismic creep, spatially correlated to active gas venting at the seafloor, occurs on the Western segment of the MMF. This segment is also capable to large earthquake ruptures such as the 1912 event. On the eastern part of the Sea of Marmara, the Istanbul-Silivri and Prince Island segments appear essentially locked. Moreover, the base of the seismogenic zone and locking depth appears to shallow (from 15-20 to 10-15 km) from west to east.

On one hand, we propose to further evaluate fault slip rates and distribution of locking ratio on individual fault segments using an elastic block model constrained by land geodesy data and marine observations (long-term fault slip rate estimates, local acoustic ranging results). On the other hand, we evaluate the temperature at the seismogenic depths by basin modelling. Results suggest that spatial variations of fault behavior in the Sea of Marmara may result from a combination of factors. First, thermogenic gas generation within the $>6 \mathrm{~km}$ thick sedimentary cover in the Western Sea of Marmara may contribute to unlock the shallow part of the fault by generating overpressures. Second, heterogeneity of the crust composition could be a factor as the North Anatolian Fault system follows the intra-pontide ophiolitic suture. For instance, long term post-seismic creep onland at Ismet Paşa has been related to the presence of serpentinite in the 
fault zone. Moreover, high-density magnetic bodies have been identified along the MMF. Third, varying thermal regimes between the Western and Eastern parts of the Sea of Marmara may account for variations in the seismogenic depths. Seafloor heat flow in the Sea of Marmara is strongly affected by sediment blanketing and basin modeling considering this process suggests that the crustal heat flow is about $20 \mathrm{~mW} / \mathrm{m}^{2}$ higher in the eastern part than in western part of the Sea of Marmara. This difference may be explained by a more spread out crustal extension in the western Sea of Marmara. 